\section{(- \\ OPEN ACCESS}

\title{
Rare case of Propionibacterium acnes-related splenic abscess
}

\author{
Subhan Mohammed, ${ }^{1,2}$ Vidya S Kollu ${ }^{1}$
}

'Department of Internal Medicine, McLaren Regional Medical Center, Flint, Michigan, USA

${ }^{2}$ Department of Neurology, University of Florida, Gainesville, Florida, USA

\section{Correspondence to} Dr Subhan Mohammed, drsubhanaziz@gmail.com

Michigan State University Flint Area Medical Education Conference May 2018 American College of Physicians Michigan Chapter Meeting 2017

Accepted 28 August 2018

\section{SUMMARY}

A 64-year-old woman with a medical history of morbid obesity, chronic hepatitis C, essential hypertension, multiple episodes of abdominal cellulitis, diabetes mellitus type 2 on insulin, intravenous and subcutaneous drug abuse presented to the emergency department complaining of left lower chest pain for 6 weeks along with multiple episodes of vomiting. Initial laboratory data revealed leucocytosis of $17200 \times 10^{3} / \mu \mathrm{L}$ with left shift. She reported multiple episodes of fever spikes. Abdominal and pelvic CT showed a splenic hypodense lesion. Specimens from interventional radiology aspiration and splenectomy grew Propionibacterium acnes. Following splenectomy, patient's symptoms resolved. To the best of our knowledge, this would represent the fifth reported case of $P$. acnes splenic abscess.

\section{BACKGROUND}

Propionibacterium acnes (P. acnes) is a relatively slow growing, anaerobic, gram-positive bacteria which is a normal flora found on the skin, oral cavity, gastrointestinal tract, conjunctiva and external ear canal. ${ }^{1-3}$ P. acnes is commonly considered a contaminant in blood cultures because of its natural habitat on human skin and, hence, is often not actively pursued. $P$ acnes can rarely cause invasive infections

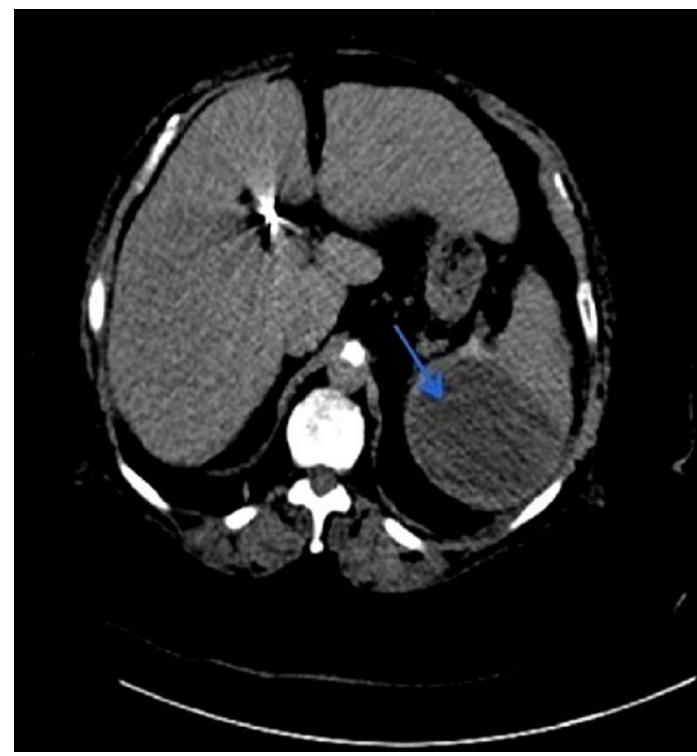

Figure 1 CT scan of the abdomen and pelvis without contrast showing hypodensity in the superior aspect of the spleen: transverse section.

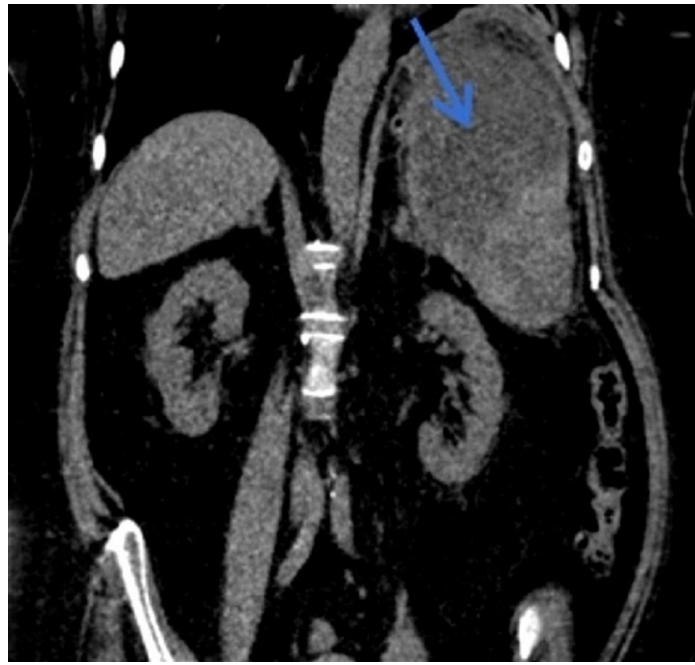

Figure 2 CT scan of the abdomen and pelvis without contrast showing hypodensity in the superior aspect of the spleen: coronal section.

like endocarditis, osteomyelitis, mediastinitis, discitis, infections of intraocular lenses, prosthetic joints and heart valves. ${ }^{34}$ This organism has been rarely associated with splenic abscess with only four known reported cases so far. ${ }^{5-8}$ To the best of our knowledge, this would be the fifth reported case.

\section{CASE PRESENTATION}

A 64-year-old Caucasian woman with a medical history significant for morbid obesity, intravenous and subcutaneous drug abuse, chronic pain, hepatitis C, diabetes mellitus type 2 on insulin, multiple episodes of abdominal cellulitis with methicillin-resistant Staphylococcus aureus, dyslipidaemia and essential hypertension presented to the emergency department complaining of intermittent lower left-sided chest and shoulder pain for the past 6 weeks. She described the pain as sharp in nature, 10 over 10 in severity, localised to the left lower side of the chest with radiation to the left shoulder tip. She said that her pain got worse with a deep breath or any movements. She denied any previous history of similar pain. She reported feeling nauseated with multiple episodes of non-bilious, non-projectile, non-bloody vomiting. Her review of systems was positive for decreased appetite, subjective fever with frequent rigours and sweats. She denied measuring her temperature at home. Social history was significant for intravenous cocaine and subcutaneous morphine 


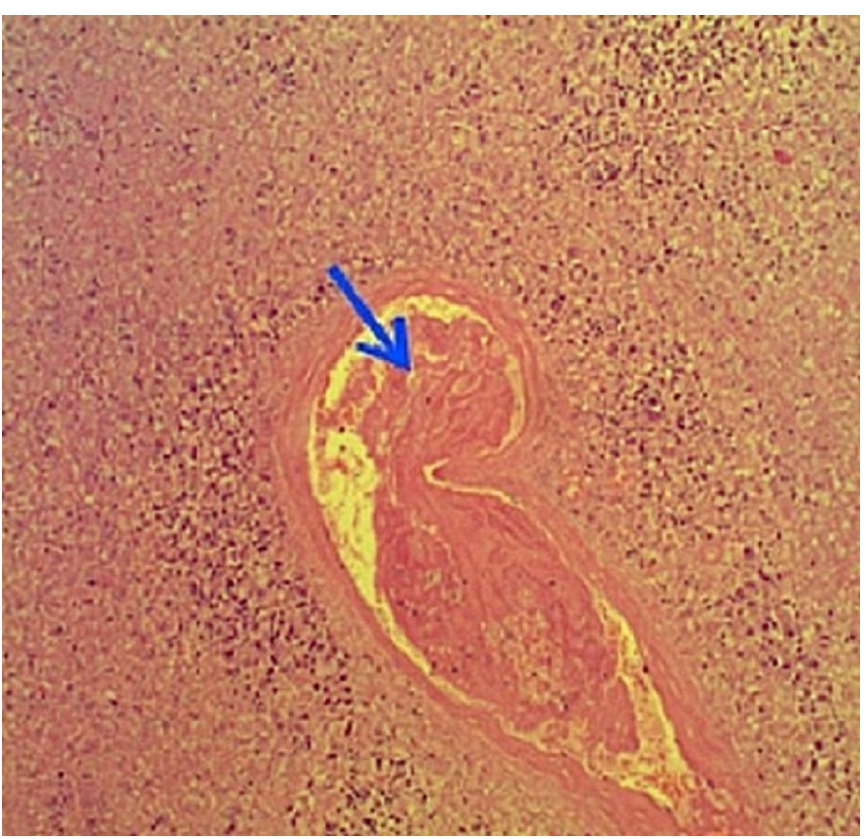

Figure 3 Histopathology of splenectomy specimen showing fibrinopurulent exudate with some congestion and haemorrhage along with surrounding fibrosis.

abuse. Family history was positive for premature coronary artery disease in her brother and pancreatic cancer in her son. On physical examination, her vital signs were as follows: blood pressure $175 / 103 \mathrm{~mm} \mathrm{Hg}$, heart rate 113 beats per minute, temperature $36.7^{\circ} \mathrm{C}$, respiratory rate 22 per minute and oxygen saturation $98 \%$ on room air. Her oral mucosa was dry. There was reproducible chest tenderness in the left lower side. Heart sounds S1 and S2 were heard without any murmurs, rubs or gallops. Lungs were clear to auscultation with good air entry bilaterally. Her abdomen appeared normal on gross inspection. Normal bowel sounds were heard in all four quadrants. There was no reproducible abdominal tenderness on superficial or deep palpation. In view of her risk factors, she was admitted to rule out acute coronary syndrome. She was kept overnight for observation on a telemetry floor where she continued to have fever spikes as high as $38.9^{\circ} \mathrm{C}$ the following day. She also reported tenderness in the left upper abdomen the next day.

\section{INVESTIGATIONS}

Laboratory data from emergency department revealed leucocytosis of $17200 \times 10^{3} / \mu \mathrm{L}$ with left shift. Posterioanterior chest X-ray on admission revealed mild to moderate leftsided pleural effusion. Initial cardiac workup was negative, including ECG, serum troponin and a transthoracic echocardiogram with a normal ejection fraction and wall movement. The negative cardiac workup and continued nausea and vomiting along with left upper abdominal pain the next day prompted an abdominal and pelvic CT scan without contrast which revealed an $8.9 \mathrm{~cm}$ hypodensity in the superior aspect of the spleen with ill-defined linear densities in the inferior and anterior aspect without surrounding fluid (figures 1 and 2). The infectious disease consultant recommended interventional radiology-guided aspiration of the hypodense splenic territory. Aspirated material was sent for aerobic and anaerobic cultures. General Surgery consultation was obtained and the patient underwent a diagnostic exploratory laparotomy. Cultures from interventional radiology (IR)-guided aspirate and splenectomy specimen were identified as $P$. acnes on a micro scan. No special tests were done to identify the subtype of $P$. acnes. Five sets of blood cultures ordered during hospital course were all negative. Transoesophageal echocardiogram done in view of the patient's history of intravenous and subcutaneous drug abuse was negative for valvular vegetations. Pathology reports from the splenectomy revealed a specimen weighing approximately $460 \mathrm{~g}$ with admixed fibropurulent exudate with some congestion and haemorrhage, consistent with abscess tissue along with some surrounding fibrosis (figure 3 ). It measured approximately $18 \times 15.5 \times 7.5 \mathrm{~cm}$. She also underwent leftsided thoracentesis for worsening pleural effusion attributed to her splenic abscess. The fluid was negative on stain and culture. Fluid analysis revealed the pleural effusion to be an exudate. Repeat chest X-ray showed resolution of the pleural effusion.

\section{DIFFERENTIAL DIAGNOSIS}

Differential diagnosis that were considered were splenic haematoma and splenic abscess. In view of fever and patient's history of drug abuse, splenic abscess was more likely a possibility. Splenic infarct can also present as a hypodense lesion on imaging but the disease course is usually more acute. Our patient had an insidious onset of symptoms which were ongoing for the past 6 weeks. She had an initial transthoracic echocardiogram which was negative for vegetations or thrombus in the

\begin{tabular}{|c|c|c|c|c|c|}
\hline Case number & Year reported & $\begin{array}{l}\text { Age and sex of the } \\
\text { patient }\end{array}$ & Risk factor & Outcome & Treatment \\
\hline 1. & 1981 & 27 year old, male & $\begin{array}{l}\text { Sickle cell trait and intravenous drug } \\
\text { abuse }^{7}\end{array}$ & Survived & $\begin{array}{l}\text { Splenectomy and } \\
\text { intravenous } \\
\text { penicillin }\end{array}$ \\
\hline 2. & 1982 & 59 year old, male & $\begin{array}{l}\text { Unclear aetiology with a history of } \\
\text { diabetes mellitus with subcutaneous } \\
\text { insulin administration }\end{array}$ & Survived & $\begin{array}{l}\text { Splenectomy and } \\
\text { intravenous penicillin }\end{array}$ \\
\hline $3^{*}$ & 2006 & Unidentified & Not mentioned ${ }^{8}$ & Unknown & Not mentioned \\
\hline 4. & 2013 & 64 year old, male & $\begin{array}{l}\text { Immunodeficiency with chronic } \\
\text { lymphocytic leukaemia }^{5}\end{array}$ & Survived & $\begin{array}{l}\text { Splenectomy and } \\
\text { levofloxacin }\end{array}$ \\
\hline Present case & 2017 & 64 year old, female & $\begin{array}{l}\text { History of diabetes mellitus } \\
\text { on insulin, intravenous and } \\
\text { subcutaneous drug abuse }\end{array}$ & Survived & $\begin{array}{l}\text { Splenectomy and } \\
\text { clindamycin }\end{array}$ \\
\hline
\end{tabular}

* Retrospective study of 67 cases with splenic abscess at one centre without specific details of individual patients. 
heart. She had no history of irregular heart rhythm. Her ECG and overnight telemetry findings were negative for irregular rhythms. This made a splenic infarct a less likely diagnosis. A transoesophageal echocardiogram performed later confirmed the findings of transthoracic echocardiogram.

\section{TREATMENT}

The following day of admission, the patient was started on empiric antibiotics with metronidazole and ciprofloxacin due to the possibility of splenic abscess. Infectious disease consultant recommended additional coverage with vancomycin in view of previous history of methicillin-resistant $S$. aureus cellulitis. A complete splenectomy was performed and the splenic bed was copiously irrigated. Leucocytosis started to improve and patient improved symptomatically. The choice of antibiotic was narrowed down to intravenous clindamycin based on culture and sensitivity reports. Intravenous clindamycin was administered for a total of 7 days.

\section{OUTCOME AND FOLLOW-UP}

The patient survived and improved clinically. Her symptoms resolved post splenectomy. No further fever spikes were reported.

\section{DISCUSSION}

The word abscess is derived from the Latin word Abscessuss, meaning 'gathering of humours'. 'In English, it refers to a walled-off cavity filled with inflammatory cells and fluids resulting in tissue destruction. It was originally described in the 16 th century. ${ }^{9}$ Abscesses can involve any organ of the body but splenic involvement is rare. In multiple autopsy series by Nelken et al, Chun et al and Reid and Lang, splenic abscesses occurred in a frequency of $0.1 \%-0.7 \% .^{10-12}$ Splenic abscesses as described by Nelkan and colleagues were rare and divided into five types: metastatic infections, contiguous infections, trauma, immunodeficiency and embolic. ${ }^{10}$ The exact cause for splenic abscess in our patient remains unclear but two possibilities are raised by other case reports. One case was reported in a diabetic where it was suggested that self-inoculation of $P$. acnes during administration of insulin might have resulted in a subclinical focus of infection. ${ }^{6}$ In another report, a patient had a history of heroin abuse. ${ }^{7}$ In our patient, subcutaneous drug abuse, multiple episodes of abdominal wall cellulitis, insulin administration or intravenous drug abuse may have been the initial source of infection.

In a splenic abscess case reported in 2013, the patient initially presented with fever of unknown origin. ${ }^{5}$ Although our patient had a subjective feeling of fever and chills, she did not record her temperature until she came to the emergency department 6 weeks later and did not have the time course or negative workup which defines 'a fever of unknown origin'. The most common organisms involved in splenic abscesses varied based on geography and time frame and included $S$. aureus, ${ }^{12}$ Klebsiella pneumoniae, ${ }^{13}$ Streptococcus viridans ${ }^{14}$ and Mycobacterium tuberculosis. ${ }^{15}$

P. acnes has been implicated in prosthetic device infections including prosthetic heart valves, ventricular shunts, orthopaedic devices, deep bone infections especially the vertebra after lumbar puncture, postoperative infections, mediastinitis and silicone implants. ${ }^{341617}$ Sickle cell disease as a risk factor for splenic abscess was reported by Cockshott and Weaver ${ }^{18}$ although only one case of $P$. acnes-related splenic abscess was reported in a sickle cell trait patient who had a history of drug addiction. $^{7}$

To the best of our knowledge, only four cases of splenic abscess caused by $P$. acnes have been reported so far. A brief review of these cases is summarised in table 1 .

\section{Learning points}

Risk factors that can lead to Propionibacterium acnes splenic abscess include diabetes mellitus on insulin, subcutaneous and intradermal drug abuse, sickle cell trait and immunodeficiency.

- Splenectomy is an effective treatment for $P$. acnes splenic abscess.

- P. acnes is usually sensitive to many classes of antibiotics including penicillin, cephalosporins, cephamycin, carbapenems, fluoroquinolones and clindamycin.

- $P$. acnes is rarely associated with invasive infections. It is a commensal found on skin and is usually treated as a contaminant when growing in cultures. When $P$. acnes is found to be growing in blood, serious evaluation for possible clinical disease should be considered.

Acknowledgements Dr Susan Jane Smith reviewed the initial draft and provided general assistance in publication. Dr Afrah Saleem reviewed the final draft for publication and suggested grammatical changes.

Contributors SM: wrote the main manuscript and was involved in literature search; actively involved in the patient care; wrote both the initial and the final draft of the manuscript. VK: assisted in literature search and revision of the manuscript.

Funding The authors have not declared a specific grant for this research from any funding agency in the public, commercial or not-for-profit sectors.

Competing interests None declared.

Patient consent Obtained.

Provenance and peer review Not commissioned; externally peer reviewed.

Open access This is an open access article distributed in accordance with the Creative Commons Attribution Non Commercial (CC BY-NC 4.0) license, which permits others to distribute, remix, adapt, build upon this work non-commercially, and license their derivative works on different terms, provided the original work is properly cited and the use is non-commercial. See: http://creativecommons.org/ licenses/by-nc/4.0/

\section{REFERENCES}

1 Public Health Image Library (PHIL). https://phil.cdc.gov/Details.aspx?pid=3083 (accessed on 22 Mar 2018).

2 Levy PY, Fenollar F, Stein A, et al. Propionibacterium acnes postoperative shoulder arthritis: an emerging clinical entity. Clin Infect Dis 2008;46:1884-6.

3 Perry A, Lambert P. Propionibacterium acnes: infection beyond the skin. Expert Rev Anti Infect Ther 2011;9:1149-56.

4 Niazi SA, Clarke D, Do T, et al. Propionibacterium acnes and Staphylococcus epidermidis isolated from refractory endodontic lesions are opportunistic pathogens. J Clin Microbiol 2010;48:3859-69.

5 Kiritani S, Kaneko J, Aoki T, et al. Multiple splenic nodules with fever: a case of splenic abscess due to Propionibacterium acnes. Clin I Gastroenterol 2013;6:434-7.

6 Gekowski KM, Lopes R, LiCalzi L, et al. Splenic abscess caused by Propionibacterium acnes, Yale J Biol Med 1982:55:65-9.

7 Gangahar DM, Delany HM. Intrasplenic abscess: two case reports and review of the literature. Am Surg 1981;47:488-91.

8 Chang KC, Chuah SK, Changchien CS, et al. Clinical characteristics and prognostic factors of splenic abscess: a review of 67 cases in a single medical center of Taiwan. World $J$ Gastroenterol 2006;12:460-4.

9 abscess. https://en. wiktionary.org/wiki/abscess (accessed on 22 Mar 2018).

10 Nelken N, Ignatius J, Skinner M, et al. Changing clinical spectrum of splenic abscess. A multicenter study and review of the literature. Am I Surg 1987;154:27-34.

11 Chun CH, Raff MJ, Contreras L, et al. Splenic abscess. Medicine 1980;59:50-65.

12 Reid SE, Lang SJ. Abscess of the spleen. Am J Surg 1954;88:912-7.

13 Ferraioli G, Brunetti E, Gulizia R, et al. Management of splenic abscess: report on 16 cases from a single center. Int J Infect Dis 2009;13:524-30.

14 Lee WS, Choi ST, Kim KK. Splenic abscess: a single institution study and review of the literature. Yonsei Med J 2011;52:288-92. 
15 Llenas-García J, Fernández-Ruiz M, Caurcel L, et al. Splenic abscess: a review of 22 cases in a single institution. Eur J Intern Med 2009;20:537-9.

16 Skinner PR, Taylor AJ, Coakham H. Propionibacteria as a cause of shunt and postneurosurgical infections. J Clin Pathol 1978;31:1085-9.
17 Petrini B, Welin-Berger T, Nord CE. Anaerobic bacteria in late infections following orthopedic surgery. Med Microbiol Immunol 1979;167:155-9.

18 Cockshott WP, Weaver EJ. Primary tropical splenic abscess: a misnomer. Br J Surg 1962;49:665-9.

Copyright 2018 BMJ Publishing Group. All rights reserved. For permission to reuse any of this content visit

http://group.bmj.com/group/rights-licensing/permissions.

BMJ Case Report Fellows may re-use this article for personal use and teaching without any further permission.

Become a Fellow of BMJ Case Reports today and you can:

- Submit as many cases as you like

- Enjoy fast sympathetic peer review and rapid publication of accepted articles

Access all the published articles

Re-use any of the published material for personal use and teaching without further permission

For information on Institutional Fellowships contact consortiasales@bmjgroup.com

Visit casereports.bmj.com for more articles like this and to become a Fellow 